\title{
Seismic Performance Evaluation between Rigid Base and Isolated Base
}

\author{
Lubna Gazal and Dr.D.K. Kulkarni
}

\begin{abstract}
The earthquakes in the Indian subcontinent have led to an increase in the seismic zoning factor over many parts of the country. Under such circumstances, seismic qualification of building has become extremely important. Several techniques are available today to control the vibration of the structure, out of which concept of using base isolators has been increasingly implemented internationally in recent years and has proven to be most promising for earthquake safety. To protect buildings against strong earthquakes isolating devices are introduced between the superstructure and the foundation. The devices act under normal circumstances as rigid connections and under earthquakes as shock absorbers. In this project work, with the help of latest available software, we shall model a frame with a rigid base and model is used to study the behavior of the frame under the action of seismic loads. This might get partially or completely damaged dueto inertia forces resulting due to the lateral displacement of the foundation. Isolating devices will be introduced between the superstructure of the building and the foundation. The devices act as rigid connection under gravity loads and shock absorbers under seismic loads. Pushover analysis iscarried out for auto hinge properties, available in SAP2000 based on the FEMA-356 and ATC-40 guidelines. The pushover analysis shows the pushover curves, capacity spectrum, plastic hinges and performance level of the building. After comparing the results of rigid frame structure with isolated frame structure, the behavior of the base isolators can be concluded at the end of the project work.
\end{abstract}

Keywords--- Capacity Spectrum, Isolators, Pushover Analysis, Plastic Hinges

\section{INTRODUCTION}

$\mathrm{I}_{\mathrm{c}}^{\mathrm{N}}$ $\mathrm{N}$ the, recent years have seen a number of occurrences of catastrophic structures failure due to severe seismic events i.e. earthquakes. So, it has been a great concern of all to make seismically strong structures. One of the widely implemented and accepted seismic protection systems is base isolation. To enhance structural safety and integrity against severe earthquakes, more effective and reliable techniques for seismic design of structures based on structural control concepts are desired. Among the structural control schemes developed, seismic base isolation is one of the most promising alternatives. Over the past decades, earthquake resistant design

\footnotetext{
Lubna Gazal, PG Student, Civil Engineering Department, SDM College of Engineering and Technology, Dharwad, India. E-mail:lubnazuf57@gmail.com

Dr.D.K. Kulkarni, Professor, Civil Engineering Department, SDM College of Engineering and Technology, Dharwad, India. E-mail:dilipkkulkarni@ rediffmail.com DOI:10.9756/BIJMMI.8158
}

of building structures has been largely based on a ductility design concept worldwide. The performances of the intended ductile structures during major earthquakes however, have proved to be unsatisfactory and indeed far below expectation. High uncertainty of the ductility design strategy is primarily attributed to the following:

1. The desired "strong column weak beam" mechanism may not form in reality, due to existence of walls.

2. Shear failure of columns due to inappropriate geometrical proportions or short column effect.

3. Construction difficult in grouting, especially at beamcolumn joints, due to complexity of steel reinforcement required by the ductility design.

Seismic isolation provides superior performance compared to traditional structural design. The isolation system accomplishes this by deforming laterally during the earthquake .after the earthquake this results in a functional structure with little or no damage. The seismic resistance of a building can be improved by changing its dynamic characteristics by introducing base isolation system. The base isolation reduces the seismic demand of the structures.

The lead rubber bearing (LRB) was invented in the 1970's and this allowed the flexibility and damping to be included in a single unit about the same time the first application using rubber bearing for isolation were constructed. For the purpose of our study and work Lead Rubber Bearing shall be used. It consists of a laminated rubber and steel bearing with steel plates which connects the structure.

\section{CONCEPT OF BASE ISOLATION}

Seismic (or base) isolation is a design technique that reduces the force demand on structures by isolating them from the damaging effect of the ground motion. It functions primarily by lengthening the period of the structure. This approach contrasts with conventional design schemes that rely on inelastic action of various structural elements to dissipate earthquake energy. Isolation reduces the force demand on the structure and thereby limits inelastic deformation; it provides a level of performance well beyond the normal code requirements with potential for substantial life-cycle cost reduction. In contrast to conventional technology, seismic isolation offers the possibility of protecting the contents and secondary features of the building because seismic forces transmitted to the structure are reduced. There has been much emphasis on the suitability of base isolation for critically important structures such as hospitals and emergency centres. For such buildings where protection of contents is critical, either because of their value or because of the need to maintain serviceability after an earthquake, seismic isolation can be an attractive option both technically and economically. 
The protection of both structure and contents, however, would be advantageous for ordinary civil structures, such as apartment blocks, particularly in areas of high seismicity. Settlements of large size help justify and make economically beneficial the adoption of base isolation. As a matter of a fact, the high number of seismic isolation devices to be used allows for a reduction of their costs (short-term saving). Furthermore, when base isolation is adopted foran entire settlement the lower seismic vulnerability can impact on the surrounding region. Last but not least, the high level of protection given by the seismic isolation assures the almost complete absence of damage and thus the avoidance of post-earthquake repairing costs, even for the design earthquake, whose probability of occurrence during the structure lifetime is significant in highly seismic areas (long-term savings).During earthquakes, the conventional structure without seismic isolation is subjected to substantial storey drift which may lead to damage or even collapse of the building. Whereas displacement endured by the isolation bearing is illustrated in fig 1 . The lateral forces of the isolated structure are not only reduced in magnitude but also fairly redistributed over the floors. This further mitigates the overturning moment of the structure.
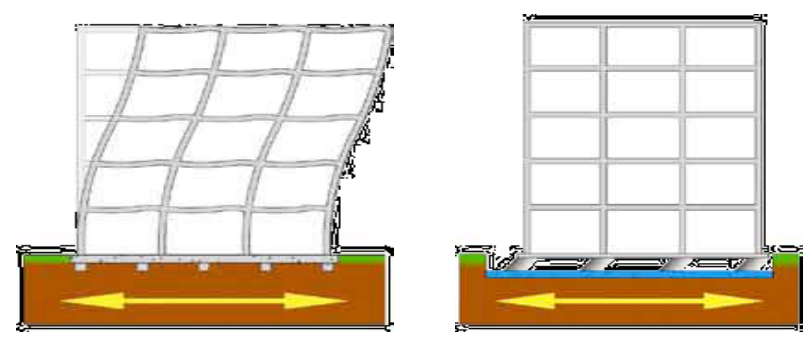

Figure 1: Conventional Building and Seismic Isolated Building

For the purpose of our study and work Lead Rubber Bearing shall be used. It consists of a laminated rubber and steel bearing with steel plates which connects the structure.

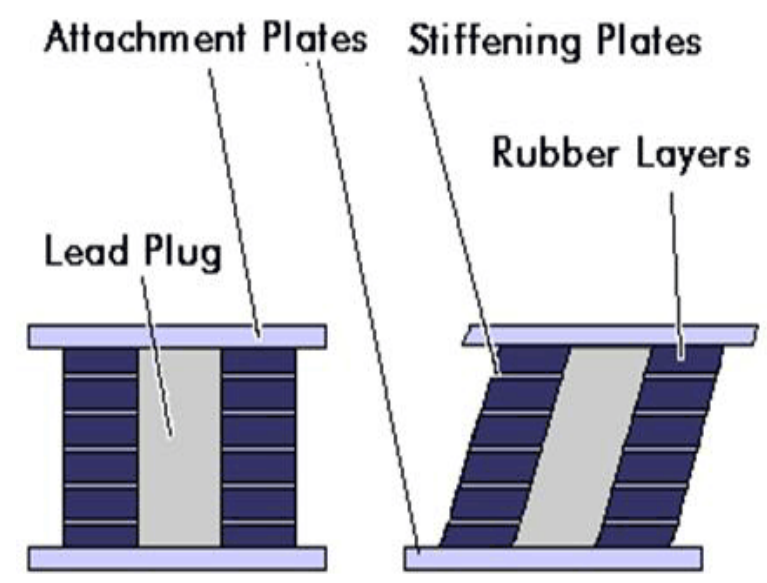

Figure 2: Lead Rubber Bearing

Lead rubber bearings were developed as base isolators in the 1970s. They consist of three basic components-a lead plug, and rubber and steel, which are generally placed in layers as shown in fig. 2 .

\section{MODELLING OF BASE ISOLATORS}

Modified values of Rubber properties:

$Q=22.832 \mathrm{kN}$

$$
\begin{aligned}
& K 2=439.823 \mathrm{kN} / \mathrm{m} \\
& K 1=4398.23 \mathrm{kN} / \mathrm{m} \\
& D_{Y}=6 \mathrm{~mm} \\
& F_{Y}=25.369 \mathrm{kN}
\end{aligned}
$$

For modelling of base isolators in SAP2000, the link support properties are choosen.

The following values of base isolators are taken as the input data in SAP2000:

Properties for Linear analysis cases:

Effective Stiffness: $439.823 \mathrm{kN}$

Effective Damping: 0.1

Distance from End-J: 0, Properties for Non Linear Analysis, Stiffness: $439.823 \mathrm{kN}$

Yield Strength: 12.549

Post Yield Stiffness ratio: 0.1

\section{OBJECTIVES}

The objective of seismic isolation systems is to decouple the building structure from the damaging components of the earthquake input motion, i.e. to prevent the superstructure of the building from absorbing the earthquake energy. The entire superstructure must be supported on discrete isolators whose dynamic characteristics are chosen to uncouple the ground motion. Some isolators are also designed to add substantial damping. Displacement and yielding are concentrated at the level of the isolation devices, and the superstructure behaves very much like a rigid body.

\section{METHODOLOGY}

The building was analyzed and designed for dead loads, wall loads and live loads. The live loads were referred from IS875 Part 2. A G+5 storey asymmetrical frame was modelled. For dead loads the self weight of the slabs, beams, columns were assigned by providing the member properties as follows:

Slab: $120 \mathrm{~mm}$ thick

\section{Beam: 230mm X 380mm}

Column: 230mm X 450mm

The wall load was been calculated and assigned on the beams. Later two models were been modelled.

Model 1 i.e., rigid base frame structure

Model 2 i.e., isolated base frame structure

In isolated base frame isolating devices will be introduced between the superstructure of the building and the foundation. 
VII. COMPARISON BETWEEN BOTH THE MODELS Model 1: Rigid Frame Structure

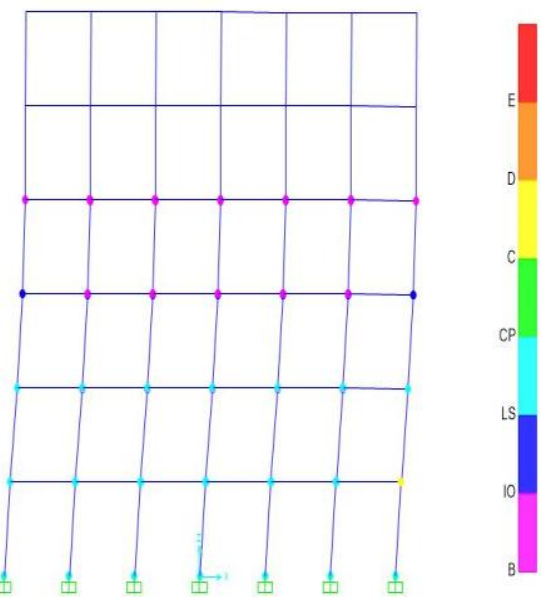

Figure 5: Formation of Hinges in the Last Step

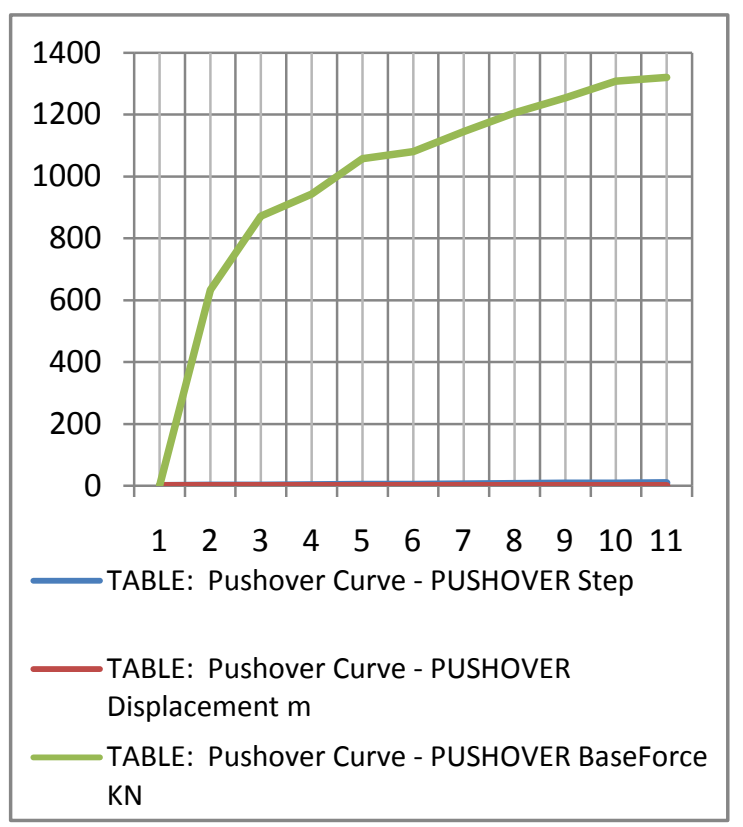

Figure 6: Pushover Curve

Model 2: Isolated base Frame Structure

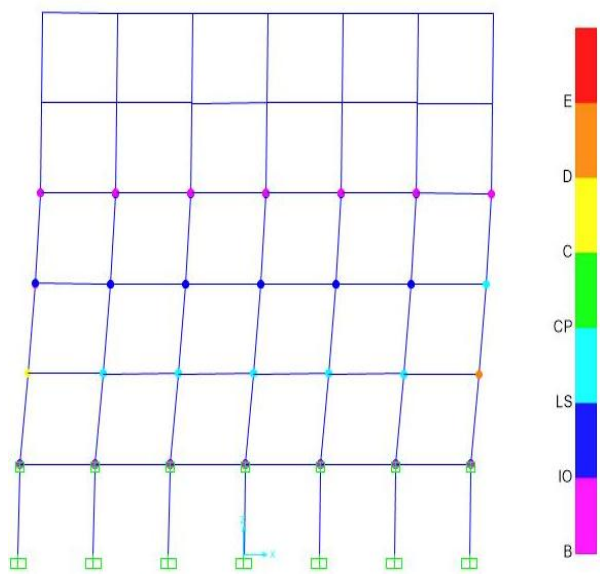

Figure 7: Formation of Hinges in the Last Step

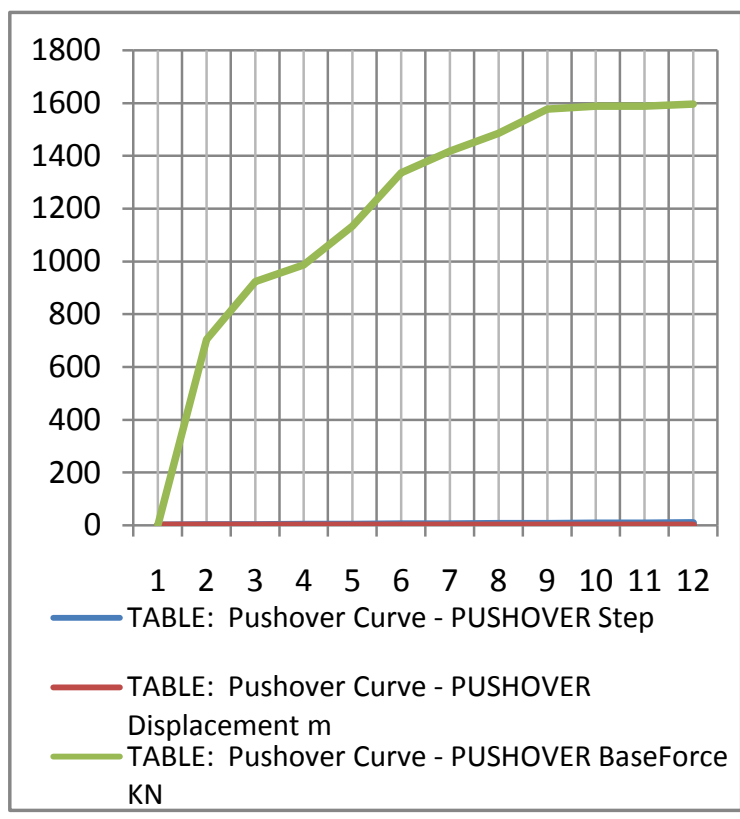

Figure 8: Pushover Curve

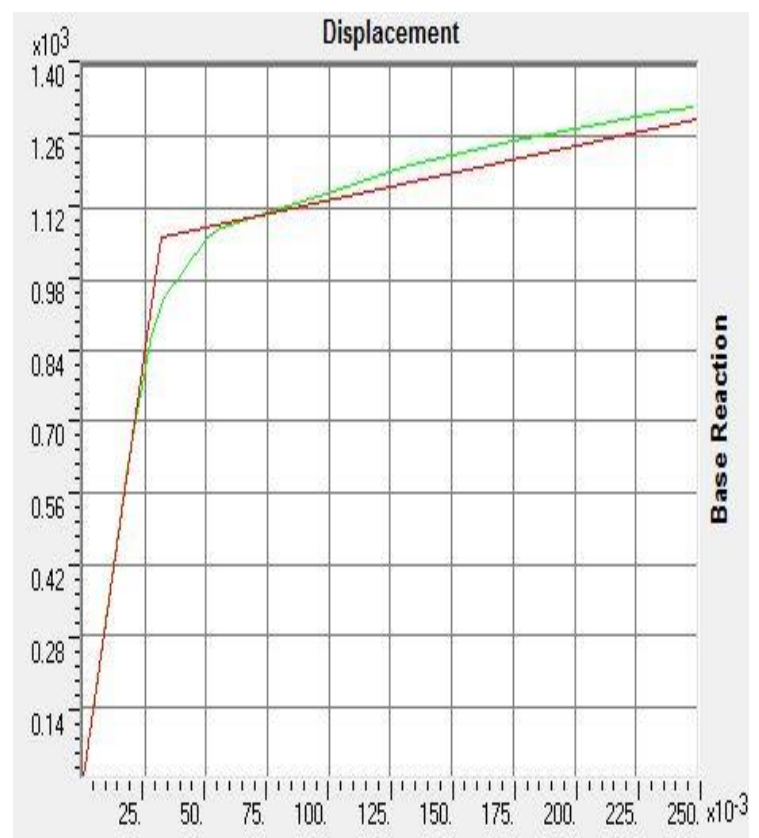

Figure 9: Bilinearization curve using FEMA356 From the graphs it's observed that,

Base Shear -1319.924kN

Displacement $-0.272 \mathrm{~m}$ 


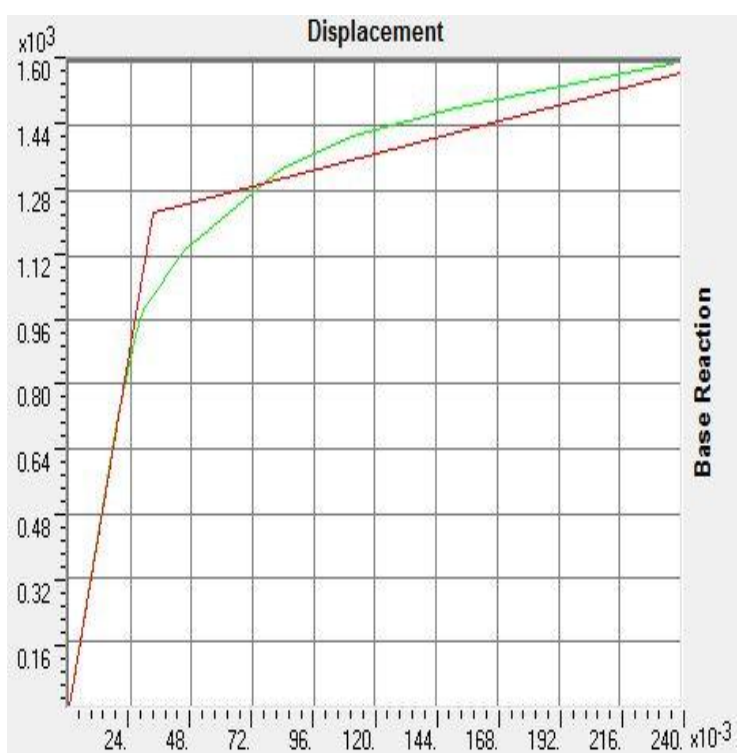

Figure 10: Bilinearization Curve Using FEMA356

From the graphs it's observed that,

Base Shear- $1596.696 \mathrm{kN}$

Displacement- $0.253 \mathrm{~m}$

\section{RESULTS AND CONCLUSIONS}

Fig.5 shows formation of hinges in the last step, fig.6 shows pushover curve, fig. 9 shows bilinearization curve using fema356 for rigid base frame.

Fig.7 shows formation of hinges in the last step, fig.8 shows pushover curve, fig. 10 shows bilinearization curve using fema 356 for isolated base frame.

From the above figures after bilinearization of pushover curve using FEMA356 the base shear for Model 1(Rigid Base Frame) and the displacement was valid. Similarly we can observe for Model 2(Isolated Base Frame) the base shear and the displacement was satisfactory as in comparison with rigid base model. From this we can conclude that for higher base shear the displacement was only $0.253 \mathrm{M}$ by providing the base isolators The pushover analysis was carried out and the formation of the hinges with the effect of isolators were displayed in the figures above.It was seen that there was no damage to the structure - very limited damage to the structure. The entire superstructure was supported on the discrete isolators whose dynamic characteristics were chosen to uncouple the ground motion. With the use of isolators in the foundation of the building the displacement and yielding are concentrated at the level of the isolation devices, and the superstructure behaves very much like a rigid body.

\section{FUTURE SCOPE}

The literature review and analysis procedure utilized in this thesis has provided useful insight for future application of SAP2000 for analysis. It helps in comparing the results with experimental results data. Modelling the RCC frame in SAP2000 software gives good results which can be included in future research. In the present study frame has been studied under monotonic loads. The frame can be studied under cyclic-loading to monitor the variation in load-deflection curves at given time history.

\section{REFERENCES}

[1]. N. Lin, W. Albert, Shenton Harry and H.S Lew, "Relative Performance of Fixed and Isolated Structures", ISBN, 1992.

[2]. Abdolrahim Jalali and Peyman Narjabadifam, “Optimum model characteristic for multi storey building isolated with LBR", Pp. 187, 2006.

[3]. ATC-40, "Seismic Evaluation and Retrofit of Concrete Buildings", Vol. 1.

[4]. International Journal of Earth Sciences and Engineering, ISSN: 22489622, Vol. 2, Pp. 832-837, 2012.

[5]. M.Z. Kaab and A. Ounis, "Influence of the damping of the seismic base isolation system LRB on the dynamic response of the isolated structures. International Journal of Civil and Structural Engineering, Vol. 1, No. 4, Pp. 817, 2011.

[6]. K. Jena, "Passive vibration control of framed structures by base isolation method using lead rubber bearing", 2010

[7]. P.P. Thakare And O.R. Jaiswal, "Comparative Study of Fixed Base and Base Isolated Building using Seismic Analysis", Vol. 4, , Pp. 520-525, 2011.

[8]. P. Poluraju, "Pushover analysis of reinforced concrete frame structure using SAP 2000", Vol. 4, Pp. 684-690, 2011.

[9]. R.S. Jangid and T.K. Datta, "Performance of base isolation systems for asymmetric building subject to random excitation", Vol. 17, No. 6, Pp. 443-454, 1995. 